\title{
IGUALDAD Y DERECHOS SOCIALES
}

\author{
Nicolás Espejo Yaksic* \\ Universidad Diego Portales
}

A Cecilia Medina y su infatigable convicción

RESUMEN: El artículo nos presenta la posibilidad de abordar a través de diversas estrategias argumentativas la existencia y la compresión de los derechos sociales, con el propósito de justificar la vigencia de dichos derechos, en el Estado Social y Democrático de Derecho. Para acometer dicha tarea se observarán dos teorías: la analítica y la teórico-crítica. Ambas representan acercamientos teóricos que ayudarán a comprender de mejor manera algunas de las principales diferencias doctrinarias que se presentan en ésta aérea de los derechos fundamentales y la filosofía política de la igualdad.

PALABRAS CLAVES: Derechos sociales - derechos subjetivos - Estado social - igualdad constitucionalización.

ABSTRACT: The article gives us a possibility to approach through diverse argumentative strategies the existence and the understanding of social Rights, with the purpose of justifying the validity of these Rights, in a social, democratic, and lawful State. To reach this, two theories will be observed: analytical theory and critical theory. Both represent theoretical rapprochements that will help to understand better some of the main doctrinal differences in the fundamental rights and political philosophy of equality area.

\section{KEY WORD: Social Rights - subjective Rights - Walfare state - Equality - Constitutionalization.}

Quisiera sugerirles que la justificación de los derechos sociales, como cualquier otra forma de argumentación, dependerá del acercamiento específico que escojamos sobre el tema. Por tanto, quisiera hacer explícitas, desde un principio, dos formas concretas de enfrentar la cuestión de la comprensión, justificación y aplicación de los derechos sociales. Se trata, por cierto, de una distinción algo estilizada y que, debido a los limites propios de este tipo de intervenciones, no pretende ser exhaustiva ni todo lo detallada que se quisiera. Con todo, insistiré en que esta distinción entre dos acercamientos teóricos diversos sobre los derechos sociales, podría ayudarnos a comprender mejor algunas de las principales diferencias

\footnotetext{
*Abogado. Licenciado en Ciencias Jurídicas y Sociales, Universidad Diego Portales, Master en Derecho Internacional de los Derechos Humanos, Universidad de Oxford, Doctor en Filosofía del Derecho, Universidad de Warwick. Profesor de Derecho Constitucional y de Derecho Internacional de los Derechos Humanos, Universidad Adolfo Ibáñez, Consultor de UNICEF-Chile y Socio Fundador de la Corporación Interés Publico (www.interespublico.cl).
} 
doctrinarias que se observan en esta área de los derechos fundamentales y la filosofía política de la igualdad.

\section{El acercamiento analítico.}

Muchos se han acercado al tema de los derechos sociales desde una perspectiva que podríamos denominar, aunque vagamente, como analítica. Pues bien, ¿En qué consiste este acercamiento analítico a la reflexión sobre ideas, reglas o instituciones morales o jurídicas?

Desde una perspectiva analítica, la tarea del teórico se focaliza en "aclarar el significado de los términos utilizados en la reflexión política, así como criticar a aquellos que los emplean de manera inconsistente. Es decir, todo debate normativo debiera comenzar por un esfuerzo de clarificación a nivel del significado. Puesto que el estudio de las palabras u oraciones morales permite indagar sobre las propiedades lógicas de lo que la gente dice, esto nos permitiría resolver si lo que ellos afirman tiene sentido, que implicaciones poseen tales dichos, en fin, si los argumentos utilizados son buenos o malos. En otras palabras, nuestros esfuerzos debieran orientarse a proporcionar una estructura lógica para nuestro pensamiento moral" (Hare 1999, p. 1).

Traducido al propósito general de esta conferencia, el acercamiento analítico nos podría llevar a sugerir que la primera función esencial del teórico de derecho abocado al estudio de los derechos sociales es de proveer de un criterio adecuado para hablar sobre los derechos sociales, precisando de este modo, en qué sentido específico ellos son "derechos" (Juan Antonio Cruz Parcero, 2007, p. 77). Así, por ejemplo, algunos enfrentan la cuestión de los derechos sociales a la luz de una teoría específica relativa a la concepción preferida sobre derechos subjetivos. Permítanme darles sólo dos ejemplos concretos de tal acercamiento analítico.

Algunos autores han sugerido que la noción de derechos sociales carece de uno de los elementos esenciales de la idea de derechos subjetivos; me refiero, a que su contenido esté constituido por una obligación de conducta determinada. (R. Guastini, 1999, 189). Es decir, los derechos sociales se caracterizarían por establecer una serie de obligaciones vagas e imprecisas -expresadas en el lenguaje de los derechos- que siempre requerirían de un esfuerzo de precisión legislativa o administrativa posterior. (Ariel A. Rojas Caballero, 2002, 582-3). Tal imprecisión normativa resultaría incompatible con la estructura básica de los derechos subjetivos fundamentales, derechos que requieren siempre de la identificación precisa de una obligación jurídica concreta (Kelsen, 1993, 132; H.L.A. Hart, 1973, 183 y; J. Raz, 1986, 170).

Otros, en tanto, han sugerido que, al carecer de garantías judiciales efectivas para exigir el cumplimiento de un deber jurídico correlativo, los derechos sociales no serían, en realidad, derechos subjetivos. Para autores como Barbalet, Guastini, Zolo o, entre nosotros, Squella, al no otorgar un poder específico para exigir el cumplimiento de un deber jurídico determinado, los derechos sociales se corresponderían, más bien, con la estructura de los denominados "derechos de papel”, las "declaraciones programáticas" o las "aspiraciones de justicia social” (Barbalet, 1988; Guastini, 1999; Zolo 1994; Squella, 2000). En otras palabras, al no ser inmediatamente justiciables, los derechos sociales carecerían, en un sentido técnico o 
estricto, de la calidad de derechos subjetivos. Podrían ser derechos morales, o cumplir un rol apelativo de aspiración político-social, mas nunca, derechos subjetivos.

Por cierto, tales formulaciones analítico-críticas a la noción misma de derechos sociales no han pasado desapercibidas. Son varios los autores que, asumiendo un acercamiento analítico similar, han tratado de contrarrestar tales aseveraciones. Así, por ejemplo, se ha sostenido que si bien es cierto que los derechos sociales han sufrido de un importante déficit en términos de su desarrollo normativo, interpretativo y dogmático (M. Scheinin, 1994, 7387), lo cierto es que no resulta sostenible afirmar que el contenido específico de los derechos sociales sea del todo indeterminado.

Antes de señalar algunos ejemplos concretos de obligaciones determinadas, quisiera volver sobre una cuestión que resulta de mucha importancia para esta crítica al carácter indeterminado de los derechos sociales. Como es bien sabido, la vaguedad o "textura abierta" del lenguaje en general se acentúa en el caso de las reglas jurídicas. Al dirigirse a clases de personas o cosas y al estar concebidas para ser vigentes durante largos períodos, las reglas jurídicas -incluidas aquéllas que reconocen derechos- resultan particularmente opacas (H. L. Hart, 1994, 155-158). A su vez, esta vaguedad resulta particularmente aguda en los "casos difíciles", es decir, en circunstancias en que: a) existe más de una norma aplicable al caso; b) en que no existe ninguna norma aplicable; c) en que la aplicación de una norma podría resulta injusta o socialmente perjudicial en el caso concreto o; d) en que existan buenas razones para modificar una decisión o interpretación anterior. Por tal razón, lejos de tratarse de una mera aplicación mecánica de su contenido formal, la definición del alcance, significado y valor específico de los derechos fundamentales -incluidos los derechos civiles y políticos- siempre requiere de un complejo proceso de interpretación judicial que sobrepasa los enunciados formales de la ley (R. Dworkin, 1984, 146-208).

Habiendo dicho lo anterior, veamos como derechos tales como a la vivienda, la salud, la educación y el trabajo, si importan el cumplimiento de obligaciones concretas. Así, por ejemplo, el derecho a la salud permite verificar que los Estados se abstengan de denegar o limitar el acceso igual de todas las personas, incluidos, los presos o detenidos, los representantes de las minorías, los solicitantes de asilo o los inmigrantes ilegales, a los servicios de salud preventivos, curativos y paliativos; entre otros aspectos fundamentales (Comité DESC, Observación General No 14: El derecho al disfrute del mas alto nivel posible de salud, Párr. 34.) El derecho a la educación, a su vez, importará verificar en sede judicial, que terceros, incluidos padres y empleadores, no impidan que las niñas asistan a la escuela y llevar a efecto (facilitar) la aceptabilidad de la educación, adoptando medidas positivas para que la educación sea culturalmente aceptable para las minorías y las poblaciones indígenas, entre otros (Comité DESC, Observación General No 13: "El derecho a la educación”, Párr. 50). Por su parte, el derecho a la vivienda adecuada faculta a los jueces para verificar la seguridad jurídica de la tenencia (en sus diversas formas), el que cada vivienda cuente con ciertos servicios indispensables para la salud, la seguridad, la comodidad y la nutrición y que los gastos personales o del hogar que entraña la vivienda sean de un nivel que no impida ni comprometa el logro y la satisfacción de otras necesidades básicas, entre otras obligaciones (Comité DESC, Observación General 4 : El derecho a una vivienda adecuada, Párr., 8). Finalmente, el derecho al trabajo permitirá revisar judicialmente prácticas de trabajo forzoso u obligatorio (especialmente a las personas y grupos desfavorecidos y marginados, en particular los niños, los presos o detenidos, miembros de 
minorías y trabajadores migratorios), garantizar niveles adecuados de aquellos derechos que permiten proteger niveles esenciales de trabajo decente o digno (como el derecho a protección judicial efectiva, derecho a sindicalización, derecho a huelga) y condenar prácticas discriminatorias en el trabajo, especialmente en contra de la mujer, las minorías sexuales y las personas con discapacidad (Comité DESC, Observación General No 18, El Derecho al Trabajo, Párr. 23).

Es decir, casi todos los elementos normativos de derechos tales como el derecho a la vivienda adecuada o al más alto nivel de salud posible, podrían ser susceptibles de alguna forma de revisión o protección judicial. (S. Leckie, 1995, 35-76; D. Brand and C. Heynes, 2005, 107-151; D. Bilchitz, 2007, 135-177). Por tanto, considero que sumadas al sostenido desarrollo interpretativo sobre el contenido normativo específico de los derechos sociales por parte de diversos tribunales nacionales, la crítica a la falta de contenido normativo específico de los derechos sociales parece fundarse, más bien, en la falta de conocimiento sobre la materia que en una cuestión de fondo.

Como es posible advertir de la literatura y prácticas judiciales más actualizadas, y que se alejan de la presentación generalmente estilizada, sobre lo que tanto activistas de derechos humanos, como tribunales nacionales e internacional realmente hacen en materia de derechos sociales, las posibilidades de revisión judicial en esta materia son muy variadas ${ }^{1}$ y pueden ir desde: 1) la mera declaración judicial de la violación de un derecho económico, social y cultural (en adelante "DESC"); 2) pasando por sentencias declarativas que solicitan el Estado la adopción de medidas: a) sin especificar cómo y sin fijar un plazo determinado, b) sin especificar cómo, pero obligando a actuar dentro de un plazo determinado; 3) a declarar la violación de un DESC, identificando las medidas específicas que deben ser adoptadas y dentro de qué plazo determinado (Cecile Fabre, 2000, p. 148 y Gerardo Pisarello, 2000, 111-135).

En otras palabras, en materia de justiciabilidad de derechos sociales, es posible reconocer desde practicas judiciales más o menos deferentes con el poder legislativo y con la administración del Estado, pasando por aquellas que incorporan la defensa de mínimos esenciales o vitales respecto de cada derecho social o finalmente, ciertas técnicas de revisión judicial que, en el contexto de la limitación estructural de los recursos, se fundan en criterios de razonabilidad.

Permítanme graficar esta cuestión con el ejemplo del denominado "test de razonabilidad" desarrollado por el Tribunal Constitucional Sudafricano. El "test de razonabilidad" surge de la práctica de control de constitucionalidad de derechos sociales del Tribunal Constitucional Sudafricano. En el contexto de la necesidad de dotar de significado a la expresión "avanzar razonablemente" hacia el pleno goce de los derechos sociales reconocidos por el texto constitucional sudafricano, el Tribunal Constitucional de este país ha propuesto en una serie de casos una particular forma de entender el rol de la judicatura en respeto de este tipo de derechos [Cfr., The Government of the Republic of South Africa and

\footnotetext{
${ }^{1}$ Una presentación acabada y actualizada de este punto, con identificación de jurisprudencia concreta, puede ser revisada en Manual sobre justiciabilidad de derechos sociales para jueces de Iberoamérica, Nicolás Espejo Yaksic (autor), Red Iberoamericana de Jueces, Centro de Derechos Humanos de la Universidad Diego Portales y OXFAM-Chile, Santiago de Chile, 2009, en: www.interespublico.cl y; Domingo Lovera, "Políticas Publicas y Derechos Sociales: En busca de un lugar adecuado para las cortes", en Derechos sociales: justiciabilidad, políticas publicas e indicadores, P. Arcidiacono, N. Espejo y C. Rodríguez (Editores), Uniandes, Editorial Siglo del Hombre, Bogota, 2009 (en imprenta).
} 
others v. Irene Grootboom and others, 2001 (1) SA 46 (CC), October 4, 2000; Minister of Health et al. vs. Treatment Action Campaign (TAC) et al. Constitutional Court of South Africa, CCT 8/02, 5 July 2002 y; Khosa v. Minister of Social Development 20046 SA 505 (CC)].

El test de razonabilidad se encuentra diseñado para permitir un grado de control judicial respecto de las decisiones tomadas por otros poderes del Estado, mientras se reconoce la necesidad de contar con un cierto margen de apreciación, con el que el órgano que decide originalmente, cuenta para llegar tomar su resolución. Así, sólo se faculta al tribunal a sustituir la decisión original con su propia decisión, en la medida en que la primera caiga fuera del margen de apreciación con el que cuenta ese órgano.

Pues bien, a la luz de esta noción general del test de razonabilidad, adviertan Uds. qué tipo de cuestiones podría revisar el tribunal. Para ser consideradas como "razonables", las medidas adoptadas deben cumplir con, a lo menos, los siguientes requisitos:

a) Las medidas deben ser comprehensivas (el programa adoptado por el Estado debe hacerse cargo de todos los aspectos críticos presentes en la realización de todo derecho social) y coordinadas (el programa debe ser coherente como un todo, identificando precisamente los distintos niveles y esferas de responsabilidad de cada institución gubernamental).

b) Deben existir los recursos financieros y humanos necesarios para implementar las medidas decretadas por el Estado (de lo contrario, la medida resultaría ser meramente formal y fútil).

c) Las medidas adoptadas por el Estado deben ser razonablemente concebidas y razonablemente implementadas (cuestión que importa que las medidas no sólo sean adoptadas en el papel, sino que, además, puedan ser efectivamente llevadas a cabo).

d) Las medidas provistas por el Estado deben ser balanceadas y flexibles -capaces de responder a las crisis y a las necesidades inmediatas, de mediano y largo plazo-.

e) Las medidas decretadas por el Estado no deben excluir segmentos significantes de la sociedad, ni dejar de considerar aquellos niveles de protección de cada derecho que han quedado fuera del plan, siendo siempre capaz de responder a los niveles de privación extrema que experimentan aquellos que viven en condiciones desesperadas.

f) Finalmente, las medidas adoptadas deben ser transparentes en el sentido de que ellas deben ser conocidas por la población, tanto durante su concepción, como cuando ellas ya han sido efectivamente implementadas.

Pues bien, considerando esta particular forma de entender la justiciabilidad de los derechos sociales, es posible advertir que los jueces no se encuentran necesariamente atrapados por la disyuntiva: "protección de niveles máximos de satisfacción de derechos sociales" $v / s$ "negativa del carácter directamente justiciable de los derechos sociales". Como lo demuestra el test de razonabilidad Sudafricano, es posible pensar y desarrollar formas de intervención judicial que resulten compatibles, tanto con los compromisos normativos de un Estado social y democrático de derecho, como con la necesaria deferencia al poder político al interior de una república democrática. ${ }^{2}$

\footnotetext{
${ }^{2}$ Para una explicación más precisa sobre la jurisprudencia Sudafricana en esta materia y su justificación como modelo adecuado de justiciabilidad, ver NICOLÁs ESPEjO YAKSIC, "Derechos sociales, republicanismo y estado de derecho: un modelo de
} 
Por tanto, creo que la cuestión sobre las diferentes formas de intervención judicial específica en materia de derechos sociales es, en realidad, una desviación consciente o inconsciente de la critica a la revisión judicial de todos los derechos constitucionales, tal y como se da en el trabajo de autores como Waldron, Kramer o Tushnet. Por tal razón, si usted es hostil a la idea de tribunales de justicia abocados a la resolución de conflictos morales complejos -como la justificación del aborto, el derecho de las parejas del mismo sexo para adoptar hijos o la estructura de redistribución de la riqueza y de las oportunidades al interior de la sociedad- es muy probable que también vea con malos ojos que los tribunales de justicia decidan casos, a su vez complejos, sobre vivienda adecuada o educación de calidad. Pero si ese es el caso, entonces la discusión que ha surgido es sobre las formas de revisión judicial en general, y no sobre la posibilidad de hacer justiciables los derechos sociales en particular.

En consecuencia, tal y como ha sugerido Gargarella, en materia de justiciabilidad de los derechos sociales el desacuerdo parecería situarse, más bien, en el modelo específico de revisión judicial al que adherimos en general y no, como algunos parecen sugerir, en la imposibilidad de hacer justiciables los derechos sociales tout court. (Gargarella, 2006, 233-251).

Finalmente, aun asumiendo que los derechos sociales carecieran efectivamente de alguna dimensión significativa de justiciabilidad -cuestión que, como se ha indicado, es posible cuestionar de modo convincente- la reducción de la noción de derecho subjetivo a la de acción o garantía procesal resulta también inadecuada. Siguiendo la distinción Alexyana entre "posición jurídica actualmente exigible" y la "posibilidad de imposición desde el punto de vista del orden jurídico" (Alexy, 1997, 168), resulta posible sostener que "la suposición de que la exigibilidad judicial es una característica constitutiva del concepto de derecho subjetivo que no distingue entre enunciados sobre derechos y enunciados sobre la protección de los derechos. En otras palabras, y tal y como indica Arango, "las razones para los derechos son condiciones necesarias de los mismos, mientras que los derechos son condiciones necesarias para su exigibilidad" (Arango, 2005, 17). En sentido inverso, y tal como han sugerido Ferrajoli (1995), Carbonell (2005) y Cruz Parcero (2007), entre otros, creer que basta con buenas razones para un derecho y que éste sea reconocido jurídicamente en la ley o en la Constitución, para que, por ese mero hecho, quede garantizado, es incurrir en el mismo tipo de error.

Lo cierto es que la protección efectiva de un derecho es siempre una cuestión de grados y no un problema de "suma cero", por lo que de la supuesta inexistencia de instrumentos procesales idóneos para reclamar el cumplimiento de los derechos sociales no parece seguirse -ni lógica, ni jurídica, ni políticamente- la imposibilidad técnica de crearlos y desarrollarlos (M. Addo, 1988, 1425; C. Courtis, V. Abramovich, 2002, 40).

En consecuencia, creo que críticas analíticas como las recién identificadas pueden ser contestadas, a lo menos en principio, de modo aparentemente exitoso. Pero, además de haber calmado nuestro instinto intelectual ¿hemos llegado a alguna parte con ello?. Seguramente, los críticos analíticos contra-atacarán nuevamente, para insistir en nuestras confusiones conceptuales e incoherencias lógicas. Y así, de acá la eternidad. Por lo mismo, para plantear la cuestión de los derechos sociales desde otra perspectiva que, espero les resulte tanto más

justiciabilidad", en Derechos sociales: justiciabilidad, politicas publicas e indicadores, P. Arcidiacono, N. Espejo y C. Rodríguez (Editores), Uniandes, Editorial Siglo del Hombre, Bogota, 2009 (en imprenta). 
interesante como práctica, sugiero enfrentar este tema desde un enfoque que denominaré como una forma de acercamiento "teórico-crítico" o "reconstructivo" sobre los derechos sociales.

2. El acercamiento teórico-crítico de los derechos sociales.

Como ustedes bien saben, la expresión "Teoría Crítica" equivale a una metáfora que puede ser usada para hacer referencia a una particular forma de orientación teórica que debe sus orígenes a Kant, Hegel y Marx, su sistematización a Horkheimer y sus asociados al Instituto para la Investigación Social de Frankfurt, y su desarrollo posterior, al trabajo liderado por Jurgen Habermas y sus sucesores (D. Rasmussen, 1999, 11). Más específicamente, según la concibo, la idea de "Teoría Crítica" -en adelante TC- intenta describir un esfuerzo teórico informado por dos elementos centrales: 1) una crítica de la dominación y; 2) una teoría de la liberación (D. Kellner, 1989, 1).

Formulado en estos términos, un análisis "crítico" de la sociedad importa tanto una comprensión estructural de la sociedad capitalista, como la identificación de un concepto normativo que pueda operar como guía para la emancipación humana. En otros términos, a diferencia de la "Teoría Tradicional", de la cual la filosofía analítica es hija, la TC se mueve dentro de una distintiva dialéctica entre inmanencia y trascendencia. Siguiendo a Marx, la TC es capaz de de dar fuerza a sus enunciados en la medida que desenmascara las tensiones y posibilidades que son, a lo menos en algún sentido, inmanentes a las configuración de la sociedad capitalista actual. Pero al mismo tiempo, la TC no sólo explica aquellos significados sedimentados en una tradición dada. La idea misma de crítica contiene un potencial radical en el sentido de que las normas válidas transcienden el contexto inmediato que las generan, agregando el necesario "valor agregado" de un punto de vista normativo (N. Fraser, 2003, 202).

En otras palabras, además de encontrarse sociológicamente informada, una TC de la sociedad debe buscar proveer de una reconstrucción, ahora normativa, de los principios políticos o morales fundamentales que subyacen a la construcción social. De ahí la importancia de incorporar un análisis de las diversas teorías de la justicia disponibles, al análisis crítico. Si este esfuerzo teórico logra sus frutos, la TC cumpliría su principal objetivo: el de construir un puente entre la teoría social y la filosofía política normativa (P. Wagner, 2003, N. Espejo, 2007).

Pues bien, una TC, o si se quiere, reconstructiva de los derechos sociales importa una doble función. En primer lugar, una teoría de los derechos sociales debe comenzar situando y comprendiendo el rol y significación que dichos derechos sociales juegan al interior de sociedades modernas y complejas. En otras palabras, sugiero la inconveniencia de un acercamiento teórico a los DESC que importe una suerte de reducción a dos polos sumamente limitados, el positivismo jurídico y la teoría moral, prefiriendo un primer acercamiento al tema que opere en torno a una teoría social de los derechos sociales. En segundo lugar, sugiero que una teoría de los derechos sociales sería incompleta si luego de situar los derechos sociales al interior de una teoría social de la realidad, no fuese capaz de reconstruir normativamente esa realidad a la luz de sus supuestos morales o éticos. 
Por decirlo de otra forma, indico que el ejercicio de 'ubicación' de los derechos sociales al interior de una teoría descriptiva de sociedades modernas debe ser acompañado de la necesidad de insistir en la labor de fundamentación político-filosófica de los derechos sociales.

Pues bien, ¿̇cuáles son los principales contornos de ese diagnóstico de lo social en el contexto capitalista actual?

Primero, déjenme compartir con Uds. sólo algunas palabras sobre la génesis de los derechos sociales:

Como es bien sabido, el 'Estado Social' y el reconocimiento asociado a los 'derechos sociales', representaron las respuestas en términos de modernización que, en una medida más o menos comprensiva, todos los viejos Estados liberales proporcionaron frente a dos fenómenos fundamentales de la época contemporánea: la industrialización, con sus diferentes implicaciones económicas, sociales y políticas y la democratización de los procesos de decisión, por otra (Baldasarre, 2001, 26).

Es decir, en la realidad jurídica concreta, los derechos sociales no surgen como categorías conceptuales altamente abstractas e ideologizadas; o sea no serian, tal y como ha indicado entre nosotros Fernando Atria, "una manifestación de un forma superior de comunidad, una en que cada uno contribuye de acuerdo a sus capacidades, y recibe de acuerdo a sus necesidades."(F. Atria, 2004) Más bien, los derechos sociales surgen como resolución política de problemas prácticos de dimensiones formidables -inseguridad y exclusión- y que, de no ser abordadas institucionalmente, corrían el riesgo de explotar. Tal fue la solución al dilema experimentado por las sociedades modernas del siglo XX: la corrección de las disfunciones del mercado, a través de una intervención pública atenta a las demandas de los votantes y compensadora de las patologías sociales más agudas (Gargarella y Ovejero, 2001, 25).

Por lo mismo, bajo la estructura tradicional del Estado social, los derechos sociales se consideran todavía como mandatos políticos o, con suerte, normas de efecto indirecto, mediato. En otras palabras, en su génesis, y a diferencia de los derechos civiles y políticos, los derechos sociales son considerados como 'derechos condicionados', cuya exigibilidad jurisdiccional resulta supeditada a una previa interposición legislativa y administrativa. De modo tal que en su génesis histórico-institucional concreta, los derechos sociales no surgen para apropiarse "en los mismos términos" que en el liberalismo, del lenguaje de los derechos. Más concretamente, sea desde la perspectiva del socialismo tradicional y autoritario -como en el caso del reconocimiento de derechos sociales en la Constitución Revolucionaria de Méxicoo sea desde la matriz general de la socialdemocracia europea, los derechos sociales siempre fueron expresamente concebidos como mandatos de optimización orientados al legislador, y no como demandas individuales contra la comunidad.

Por tal razón es que la construcción del Estado social tradicional viene a profundizar, en lo referente a derechos sociales, el positivismo legalista afincado en la idea de un poder legislativo políticamente omnipotente que termina cediendo frente a intervenciones de tipo corporativo o residual y que deja a estos derechos expuestos a la comisión de delitos, la generación de daños ecológicos o el diseño de políticas asistenciales que resultan estigmatizar 
a la mujer, los niños, niñas y adolescentes, las minorías étnicas y otros grupos socialmente devaluados (G. Pisarello, 2003, 28-29).

Pero ¿Qué hay con la realidad actual de los derechos sociales en el contexto capitalista contemporáneo?

Desde luego, podríamos identificar varias características o condiciones estructurales de nuestras sociedades modernas. Hacer esto de un modo medianamente riguroso excedería, por mucho, el propósito central de esta pálida presentación. Con todo, me parece que como hipótesis de trabajo inicial, podríamos decir algunas cosas.

Primero, se podría sugerir que parece existir un cierto acuerdo generalizado en torno a la convicción política de que el sistema de gobierno basado en elecciones populares y derechos civiles y políticos básicos parece ser la única forma legítima de gobierno a nivel mundial. (T. Frank, 1992; G.H. Fox, 1999, Carta Democrática Interamericana). Con todo, tal convicción política parece no llegar sola.

Esta aparente convicción política en torno al sistema democrático ha venido acompañada, como contraparte, de un proceso de concientización similar a nivel de las instituciones económicas nacionales y globales: los pueblos pueden optar por el modelo democrático que quieran, sea éste performativo, procedimental, deliberativo, o inclusive multicultural. Sin embargo, tal modelo político debe asumir la superioridad funcional del mercado capitalista a nivel económico. Como señala Dryzek, en lo político, usted puede elegir entre diversas formas de democracia, mientras que en lo económico, usted se ve forzado a escoger entre distintas formas de capitalismo (Dryzek, 2000).

Adicionalmente, y de una directa relevancia para la continuidad de la génesis histórica de los derechos sociales que he indicado antes, parece existir un cierto acuerdo sobre la existencia de los enormes desafíos que el Estado social clásico - si ustedes prefieren, Estado de Bienestar- enfrenta en el contexto político y económico actual. Si bien, este no es lugar para discutir en profundidad lo que se ha venido en denominar como "crisis del Estado social o del estado de bienestar", sobre lo que realmente me interesa llamar la atención es lo siguiente: Aún cuando creamos que trabajo y producción no constituyen ya mas los puntos nodales de las estructuras sociales y de la transformación de la sociedad (J. Habermas, 1989, 48-70), incluso cuando pensemos que la creciente hibridización de lo social marca el fin de la 'sociedad de clases' y su reemplazo por estructuras de jerarquización que se presentan bajo el vago rótulo de 'estratificación social' (J. Pakulsky, 2006), lo cierto es que las condiciones de inseguridad, inestabilidad y exclusión económica, social, cultural y política que dieron lugar al Estado de Bienestar, siguen plenamente vigentes y, en muchos casos, agudizándose.

Por cierto, las demandas por la justa redistribución de bienes y oportunidades no es la única reivindicación legítima al interior de las sociedades capitalistas contemporáneas. Junto a ellas existen otras demandas legítimas vinculadas a lo que genéricamente podríamos identificar bajo la idea de la "política del reconocimiento" (Benhabib, 2002). Aunque tales demandas por el reconocimiento resultan relevantes no sólo para los aspectos vinculados con la identidad individual y grupal, sino también, como agudamente lo advertido Axel Honneth, con la idea de derechos sociales (Honneth, 1995), deseo concentrarme específicamente en aquellos aspectos de la sociedad actual que, de un modo preponderante, se vinculan con la idea de redistribución (Fraser, 2003). 
Contra los optimistas pronósticos de los defensores del Consenso de Washington, tanto la pobreza como la mala distribución de la riqueza siguen siendo elementos estructurales del orden global. No está demás repetir estas cifras una y otra vez: la mitad de la población mundial vive con menos de U\$2 al día, y 1/5 de la población con menos de U\$1 al día, en circunstancias que el ingreso en los 20 países más ricos es 37 veces superior al de los 20 países más pobres (World Bank, 2001).

En el caso de Latinoamérica, el crecimiento en la década de los años 90 fue débilmente superior a la mitad del crecimiento experimentado durante los 60 y 70, la tasa de desempleo superior en tres puntos y el porcentaje de la población que vive en condiciones de pobreza -esto es, con no más de U\$2 por día- es mayor (Stiglitz, 2003, 51).

En el caso de Chile, si bien sabemos que los niveles de pobreza han disminuido considerablemente durante los últimos años, aún mantenemos al 13,7 \% de nuestros compatriotas viviendo bajo la línea de pobreza ( $\$ 47.099$ pesos al mes) y al 3,2\% en condición de indigencia (\$23.549 pesos), (Casen 2007). No sólo eso, con los niveles exhibidos en materia de distribución de la riqueza, uno se pregunta si es que se puede hablar en Chile de un proyecto democrático medianamente compartido. Si midiéramos a los chilenos por sus ingresos, más de 1.500.000 de chilenos tendría una altura menor a los 20 centímetros, mientras que el candidato presidencial Sebastián Piñera -al año 2005- unos 7.152 metros, el equivalente a 56 veces la altura de la Torre ENTEL, en la ciudad de Santiago de Chile. Y eso que no es el más alto (Espejo y Mery, 2005).

En este contexto, el gran desafió que una teoría social de los derechos sociales enfrenta es la de dar debida cuenta de las condiciones estructurales de pobreza, inequidad y violencia material y simbólica que gran parte de nuestras poblaciones experimenta, y que nos les permite satisfacer aquellos niveles básicos de alimentación, salud, educación, vivienda, y dignidad laboral, entre otros. Pero al hacer esto, debemos evitar celebrar acriticamente las deficiencias y distorsiones provocadas por las instituciones clásicas del Estado social de bienestar que reducen la idea de derechos sociales a unas garantías legales o administrativas meramente programáticas.

\section{¿Cómo lograr este cometido?}

Mi sugerencia es que tal empresa teórico-práctica comienza por defender, donde exista, y consolidar, donde no éste aún no encuentre concreción institucional efectiva, el Estado Social Democrático de Derecho.

Como ya he sugerido unos minutos atrás, el Estado social clásico opera, en palabras de Esping Andersen, "con una mano izquierda que se ocupa de la cuestión social y una mano derecha que se encarga de garantizar intereses económicos de tipo privado." Esto es "desmercantiliza, por un lado, una serie de bienes y servicios que se convierten en el eje central de la ciudadanía social keynesiana. Pero actúa, por otro, como un instrumento de asentamiento del principio de mercado y de generación de mercados secundarios, favoreciendo de ese modo los procedimientos de acumulación privada." (G. Espin Andersen, 1993). Pero un corolario de este Estado de dos manos, es que, el mismo, importa una concepción restringida de Estado constitucional. 
A pesar de que permite reforzar espacios de democracia social, el Estado Social siempre se ha mostrado propicio a la multiplicación de espacios de legalidad atenuada y decisionismo administrativo que importan la suspensión de los principios de generalidad y abstracción que inspiran la noción de ley en el Estado de derecho clásico (G. Pisarello, 2003, 29). A tales manifestaciones de intervencionismo corporativo y de erosión de la participación ciudadana ha de sumarse, también, la colonización del mercado en el entramado administrativo y político y sus efectos en la privatización de los espacios públicoinstitucionales (Habermas, 1998).

Pero la alternativa del Estado Social Clásico no es la única que tenemos a nuestra disposición. A diferencia del Estado Social clásico, en el Estado Social Democrático de Derecho (o Estado Social Constitucional) los derechos sociales dejan de ser concebidos como derechos programáticos, y pasan a tomar la estructura y contenido de los derechos fundamentales; es decir, se consideran como "posiciones tan importantes que su otorgamiento o no otorgamiento no puede quedar en manos de la simple mayoría parlamentaria". (Alexy, 1997, 406). Tal definición de derecho fundamental posee una principal virtud: asocia directamente el concepto de derecho fundamental al concepto de democracia. (Arango, 2005, 31), permitiéndonos así, transitar desde acercamiento puramente analítico, al normativo.

Si esta definición general de derecho social parece atractiva, entonces quedará preguntarse por aquello que otorga, a estos derechos en particular, su peculiar "importancia". Acá, las posibles respuestas son varias, aunque sólo quiero, ya para ir concluyendo, indicarles algunas de ellas.

En otro lugar ya he tenido la posibilidad de indicar algunas vías posibles de justificación sobre la importancia de los derechos sociales (Espejo, 2005; Courtis y Espejo, 2007). Entre otras, considero que la particular importancia de los derechos sociales radica en que ellos garantizan, al mismo tiempo, libertad, auto-respeto y las condiciones de inclusividad discursiva necesarias para la constitución y el mantenimiento de un Estado Social Democrático de Derecho.

Garantizan libertad, porque los derechos sociales permiten transitar desde la defensa burguesa vacía y formal de la libertad, hacia la satisfacción de un estado básico de libertad fáctica. Como lo ha permitido advertir a nivel teórico el Marxismo Analítico y a nivel práctico la experiencia constitucional Alemana o la Colombiana, los derechos sociales pueden ser considerados una prestación jurídica garantizada iusfundamentalmente si: a) la exige muy urgentemente el principio de libertad fáctica, y b) el principio de la división de poderes y el de la democracia (que incluye la competencia presupuestada del Parlamento) al igual que c) principios materiales opuestos (especialmente aquéllos que apuntan a la libertad jurídica de otros) que son afectados en una medida relativamente reducida por vía de la garantía iusfundamental de la posición de prestación jurídica y las decisiones del Tribunal Constitucional que la toman en cuenta. En todo caso, para esta visión, estas condiciones están satisfechas en el caso de los derechos fundamentales sociales mínimos, es decir, por ejemplo, un mínimo vital, a unja vivienda simple, a la educación escolar, a la formación profesional y a un nivel mínimo de asistencia médica (Alexy, 2000, 67-85).

En otras palabras, así concebidos, los derechos sociales pasan a desempeñar un papel determinante en la coherente defensa del ideal de libertad como no-dominación o como 
"libertad real o fáctica"; ellos reconocen, por medio de la forma específica de los derechos, la obligatoriedad de ciertas prestaciones sociales básicas y la necesidad de otorgar protección especial (no dominada) a las minorías excluidas o desfavorecidas desde una perspectiva económica y social.

A su vez, los derechos sociales garantizan auto-respeto, toda vez que ellos blindan a los sujetos de aquellas formas de humillación consistente en la negación de sus derechos y el ostracismo social. Comparadas con las formas de reconocimiento fundadas en el amor, y que se representan en la forma de relaciones íntimas, esta distintiva forma de reconocimiento está dotada de un particular carácter cognitivo: ego y alter se reconocen mutuamente como personas legales, en el hecho que ellos (o ellas) comparten un conocimiento común de aquellas normas en virtud de las cuales la comunidad les asegura los derechos y responsabilidades a las que se encuentran igualmente dotados o dotadas. Esta forma de reconocimiento legal, fundada en la dignidad universal de la persona, representa la estructura tri-partita de los derechos civiles (que garantizan libertad); políticos (que garantizan participación) y; sociales (que garantizan bienestar básico), (A. Honneth, 1995).

Finalmente, los derechos sociales garantizan inclusividad discursiva, puesto que, a lo menos desde una perspectiva deliberativa de la democracia, ellos son concebidos no sólo como herramientas jurídicas para garantizar la libertad fáctica o niveles de vida dignos a favor de los ciudadanos. Si es que la democracia parece definirse más bien por su preferencia procedimental a favor de mecanismos inclusivos y participativos de deliberación pública (sólo son legítimas aquellas decisiones públicas o leyes que son el resultado de un proceso abierto, igualitario e inclusivo de diálogo colectivo) entonces los derechos sociales pueden ser vistos, junto a los derechos civiles y políticos clásicos, como poderes orientados a garantizar las condiciones materiales y normativas de la deliberación abierta, igualitaria e inclusiva.

En otras palabras, para que la deliberación tenga lugar bajo condiciones de igualdad esto es, que no sea distorsionada o ideológica se requiere de mecanismos institucionales que garanticen y preserven las condiciones de inclusión democrática que sirven de base al diálogo democrático. Como bien sabemos, bajo condiciones de marginalidad política, cultural y social, los sujetos difícilmente podrán ser vistos como pares en la deliberación. Si esto es así, entonces los derechos sociales pueden ser entendidos entonces como medios jurídicos concretos que, siempre y cuando se tome en cuenta el complejo equilibrio existente entre función judicial y función política, garanticen las condiciones básicas que permiten a los ciudadanos formar parte de una comunidad de diálogo fundada en la igualdad y la inclusión (Gargarella 2006).

Pues bien, esta evidente importancia que adquieren los derechos sociales -y que los torna en derechos subjetivos fundamentales- implica, a su vez, la necesidad de garantizar su mandato. Y en un estado social y democrático de derecho, ello se logra por medio de un complejo entramado de garantías, tanto políticas como jurisdiccionales, destinadas a actualizar los imperativos de igualdad social que ahora resultan representadas también, por la noción de derechos sociales. Así, y en primer término, es necesario garantizar la provisión de partidas presupuestarias adecuadas, que -en la lógica de la división de poderes de la democracia republicana y representativa- se centra en la discusión y aprobación pública de las leyes de presupuesto. La existencia de partidas presupuestarias adecuadas, constituye una demostración 
de la seriedad con la que los poderes políticos toman la implementación de sus obligaciones en materia de salud, educación, vivienda y otros.

Sin embargo, tales garantías políticas deben ser debidamente complementadas por garantías jurisdiccionales, las que otorgan a los titulares de derechos la capacidad de someter denuncias de incumplimiento de las obligaciones emanadas de esos derechos ante un poder independiente de los sujetos - públicos o privados- obligados y, dado el caso, confieren competencia a ese poder independiente para forzar el cumplimiento y establecer reparaciones o sanciones (Ferrajoli, 2000; Abramovich y Courtis, 2002 y; Pisarello 2003). Se trata de garantías secundarias, es decir, garantías que sólo entran en juego cuando los poderes encargados de concretar e implementar derechos incumplen con su obligación -lo que implica, a su vez, que las garantías políticas han fallado. Recién entonces cobra sentido la posibilidad de reclamo judicial de los derechos sociales, tal y como he sugerido siguiendo el modelo de razonabilidad Sudafricano. Siguiendo la lógica contractual, podría decirse que la solución de controversias vinculadas con alegados incumplimientos se inicia con el diálogo entre los contratantes, y -dado el carácter contencioso, los costos y el tiempo que puede insumir este recurso- sólo cuando queda claro que no hay solución posible por otra vía se acude al litigio judicial. ${ }^{3}$

\section{Conclusión}

Permítanme recapitular algunas de las cuestiones centrales que he intentado discutir ante Uds. en esta breve presentación. He sugerido, en primer término, que existen distintas maneras de acercarse a la cuestión de los derechos sociales y que, en un sentido relevante, el resultado de nuestras conclusiones depende del procedimiento de análisis que escojamos. He agregado existen a lo menos dos formas concretas de intentar comprender, justificar y aplicar los derechos sociales: la analítica y la teórico-crítica. Desde la perspectiva que he intentado defender esta tarde, el acercamiento analítico a los derechos sociales resulta tanto impreciso como inadecuado. Lo anterior, toda vez que un análisis más detallado sobre el contenido y las formas de justiciabilidad de los derechos sociales permite rechazar el escepticismo en torno al contenido obligacional de los derechos sociales como su supuesta instrumentalización para el activismo judicial. Esta visión crítica sobre la perspectiva analítica acerca de los derechos sociales ha sido complementada por una segunda forma de encarar la justificación y comprensión de los derechos sociales y que en mi opinión, resulta más iluminadora que la primera: la perspectiva teórico-crítica. La perspectiva teórico-crítica permite reconstruir, tanto histórica como normativamente la génesis, transito y futuro de los derechos sociales, de un modo que permita situarlos al interior de la gramática de los sistemas democráticos modernos. En particular, una concepción teórico-critica de los derechos sociales no solo resulta históricamente informada, sino que localiza a dichos derechos en el tránsito normativo de superación (en el sentido hegeliano), desde un modelo de democracia liberal en un contexto

\footnotetext{
${ }^{3}$ Para la utilización de la metáfora del contrato social y sus implicancias para las condiciones de la cohesión social contemporánea, ver, COURTIS, Christian y EsPejo, NiCOlás. Por un contrato de cohesión social: apuntes exploratorios, [en línea] Santiago de Chile, CEPAL, División de Desarrollo Social, Serie Políticas Sociales 129. <http://www.eclac.org/publicaciones/xml/3/28463/sps_LCL2699.pdf>
} 
de inequidad social, hacia la construcción de un Estado social y democrático de derecho. Tal tránsito, a su vez, importará la constitucionalización de los derechos sociales y su exigibilidad, tanto política como jurisdiccional. 